\title{
Perfil do Pequeno Produtor Referente ao Cuidado e Uso de Agrotóxicos em Sinop, Mato Grosso
}

\section{Small Farmer Profile Regarding the Care and Use of Pesticides in Sinop, Mato Grosso}

\author{
Marliton Rocha Barreto*a; Maira Luiza Spanholib; Marcos Vinicius Saraiva ${ }^{\mathrm{a}}$ \\ ${ }^{a}$ Universidade Federal de Mato Grosso. MT, Brasil. \\ bUniversidade do Estado de Mato Grosso, Programa de Pós-Graduação em Ciências Ambientais. MT, Brasil. \\ *E-mail: mrb.ufmt@gmail.com
}

\begin{abstract}
Resumo
A utilização de defensivos agrícolas por produtores rurais é muito comum, inclusive em propriedades menores, mas um dos problemas oriundos desse manuseio é a falta de preocupação do produtor em utilizar os equipamentos de segurança necessários, originando problemas de saúde. Dessa forma, o presente artigo teve como objetivo realizar um diagnóstico do cuidado e uso de agrotóxicos em pequenas propriedades rurais no município de Sinop (MT), realizado por meio de entrevista e de questionário com perguntas semiestruturadas. Constatou-se que a maioria dos produtores rurais era homens entre 46 a 60 anos, com baixa escolaridade, que cultivavam verduras, hortaliças, soja, milho e criavam gado em pequenas áreas rurais. Como em outros trabalhos de percepção e etnoconhecimento de produtos fitossanitários, a assistência técnica não abrangeu todas as propriedades rurais entrevistadas, embora os produtores tivessem cuidado tanto no manuseio, quanto ao respeito à legislação dos agrotóxicos vigente, como o uso de equipamentos de proteção individual (EPIs), a tríplice lavagem, ao armazenamento e devolução de embalagens vazias. Nessa área predomina a agricultura familiar, mas utilizam as mesmas práticas produtivas de grandes propriedades. Diante do exposto, é possível concluir que mesmo apresentando baixa escolaridade e pouca informação técnica, o agricultor usa do seu conhecimento adquirido durante a vida e experiência para utilizar de forma mais adequada o uso dos agrotóxicos.
\end{abstract}

Palavras-chave: Agroquímicos. Agricultor Familiar. Etnoconhecimento. Percepção.

\begin{abstract}
The use of pesticides by farmers is very common, even on smaller properties, but one of the problems arising from this handling is the lack of the producer's concern to use the necessary safety equipment, leading to health problems. Thus, this article aimed to make a diagnosis of the care and use of pesticides in small rural properties in the municipality of Sinop (MT), conducted by interview and use of a questionnaire with semi-structured questions. It was found that the majority of the rural producers were men between 46 and 60 years old, with low educational lever, who grew mostly vegetables, soybeans, corn and raised livestock in small areas. As in other studies on perception and ethno-knowledge of plant protection products, technical assistance did not cover all of the interviewed rural properties, although producers were careful to handle, regarding the applicable pesticide legislation, such as the use of personal protective equipment (PPE), triple washing, storage and return of empty packaging. Family agriculture predominates, but they use the same productive practices as large farms. In view of the above, it can be seen that despite the low educational level and poor technical information, the farmer uses his knowledge and experience as the most appropriate way to use pesticides.
\end{abstract}

Keywords: Agrochemicals. Ethnoknowledge. Family Farmer. Perception.

\section{Introdução}

No sistema convencional, os agrotóxicos são a principal forma de controle de pragas e doenças (ALENCAR et al., 2013) em função de seu fácil acesso e utilização, além da rápida ação (NETTO; DEGRANDE; MELO, 2014). Porém, seu uso indiscriminado pode resultar em intoxicações, em diferentes graus, de agricultores e de consumidores, tornandose um problema de saúde pública (MENDES et al., 2014).

Com isso, os casos de contaminação por agrotóxicos são recorrentes, especialmente, em populações de pequenas comunidades rurais, nas quais a maioria dos trabalhadores tem nível de instrução inadequado para o desempenho da função. Tendo em vista que a capacidade de leitura do rótulo e entendimento dos procedimentos adequados de preparação e aplicação dos produtos é uma condição indispensável para o manejo e aplicação dos agrotóxicos de forma correta
(VEIGA et al., 2007). Além disso, o desconforto no uso de Equipamentos de Proteção Individual (EPIs) pode se tornar um empecilho na sua utilização.

Uma alternativa para isso é a agricultura sustentável, produtiva e ambientalmente equilibrada. Infere-se, neste sistema, o uso do controle biológico, uma alternativa promissora para o manejo de pragas e de doenças em sistemas agrícolas sustentáveis, conhecidos também como inimigos naturais ou agentes de controle biológico (MENEZES, 2006).

No Brasil, relacionado ao desenvolvimento rural pode ser feito um recorte, no qual de um lado se encontra a agricultura convencional modernizada, centrada na grande empresa agropecuária, e do outro lado a agricultura familiar e o reconhecimento de suas particularidades (DELGADO; BERGAMASCO, 2017).

Nesse sentido, sobre a agricultura familiar, Salamoni 
(2015) afirma que esta "tem grande potencial para promover o desenvolvimento rural sustentável, não somente por ser responsável pela preservação e fortalecimento dos sistemas de produção agroecológicos, mas por ser detentora de um patrimônio cultural que lhe confere um caráter particular de organização interna". Desta forma, o presente artigo teve como objetivo realizar um diagnóstico do cuidado e uso de agrotóxicos em pequenas propriedades rurais no município de Sinop - MT.

\section{Material e Métodos}

O trabalho foi realizado no município de Sinop, Mato Grosso, inserido na região do Médio Norte mato-grossense, possuindo característica de intensa produção agrícola de soja, milho e algodão, com o uso de altas tecnologias (FARIAS, 2017).

Foram realizadas 53 entrevistas (CEP Parecer: 2.902.137) em propriedades rurais do município entre julho e agosto de 2017 e foi analisado como os agricultores lidam com os agrotóxicos, em suas propriedades, no dia a dia. Para tal, perguntas do tipo semiestruturadas (Quadro 1) foram elaboradas, para gerar uma uniformidade no trabalho realizado e facilitar as respostas do produtor.

Quadro 1 - Questionário sobre as formas de utilização de produtos fitossanitários nas propriedades rurais em Sinop, MT

\begin{tabular}{|c|c|}
\hline $\mathbf{N}^{\mathbf{0}}$ & Questão \\
\hline 1 & Quais as culturas produzidas? E a área? \\
\hline 2 & $\begin{array}{l}\text { Na sua propriedade (área) os equipamentos de proteção } \\
\text { individual (EPIs) são usados? }\end{array}$ \\
\hline 3 & $\begin{array}{l}\text { O que é feito quando sobra calda no tanque/ } \\
\text { pulverizador/bomba? }\end{array}$ \\
\hline 4 & Costuma fazer a tríplice lavagem? \\
\hline 5 & Você devolve as embalagens vazias? \\
\hline 6 & Onde são armazenadas as embalagens vazias? \\
\hline 7 & Você recebe assistência técnica? \\
\hline 8 & $\begin{array}{l}\text { Em relação à assistência técnica é assistido por alguma } \\
\text { instituição? }\end{array}$ \\
\hline 9 & Na sua área, é respeitado o uso de agrotóxicos? \\
\hline 10 & Costuma respeitar o registo dos agrotóxicos? \\
\hline 11 & $\begin{array}{l}\text { Já ocorreram casos de intoxicação, por agrotóxicos, na } \\
\text { propriedade (área)? }\end{array}$ \\
\hline 12 & Você utiliza a rotação de cultura na sua propriedade? \\
\hline 13 & Você já ouviu falar em controle biológico de pragas? \\
\hline 14 & $\begin{array}{l}\text { Já utilizou alguma técnica de controle biológico em } \\
\text { sua propriedade? }\end{array}$ \\
\hline 15 & $\begin{array}{l}\text { Gostaria de utilizar o controle biológico em sua } \\
\text { propriedade/área? }\end{array}$ \\
\hline
\end{tabular}

Fonte: Dados da pesquisa.

Os entrevistados foram selecionados utilizando a técnica chamada Bola de Neve (amostragem não probabilística), em que o primeiro entrevistado é escolhido de forma intencional, e a partir desse contato serão indicados outros entrevistados (VINUTO, 2014) e assim sucessivamente. No caso deste estudo, geralmente, as propriedades vizinhas eram indicadas. Os dados obtidos nas entrevistas foram armazenados em um banco de dados em Microsoft Excel (Office 2013), a partir disso foram gerados gráficos e quadros que deram suporte às discussões.

\section{Resultados e Discussão}

\subsection{Perfil socioeconômico}

Com relação ao gênero dos entrevistados, foi verificado que a maioria dos proprietários rurais e responsáveis pelas atividades agrícolas é do gênero masculino, totalizando 41 dos 53 entrevistados (Quadro 2).

Quadro 2 - Perfil socioeconômico dos produtores rurais entrevistados no município de Sinop - MT

\begin{tabular}{|c|c|c|c|}
\hline \multicolumn{2}{|c|}{ Descrição } & \multirow{2}{*}{$\begin{array}{c}\begin{array}{c}\text { Entrevistados } \\
\text { (n) }\end{array} \\
12 \\
\end{array}$} & \multirow{2}{*}{$\begin{array}{c}\mathbf{\%} \\
22,64 \\
\end{array}$} \\
\hline Gênero & Feminino & & \\
\hline & Masculino & 41 & 77,36 \\
\hline \multirow[t]{4}{*}{ Faixa etária } & 18 a 30 & 7 & 13,21 \\
\hline & 31 a 45 & 13 & 24,53 \\
\hline & 46 a 60 & 23 & 43,40 \\
\hline & 61 a 75 & 10 & 18,87 \\
\hline \multirow[t]{5}{*}{ Escolaridade } & $\begin{array}{l}\text { Fundamental } \\
\text { incompleto }\end{array}$ & 25 & 47,2 \\
\hline & $\begin{array}{l}\text { Fundamental } \\
\text { completo }\end{array}$ & 2 & 3,7 \\
\hline & Médio incompleto & 12 & 22,5 \\
\hline & Médio completo & 3 & 5,7 \\
\hline & Superior & 11 & 20,9 \\
\hline \multirow{2}{*}{$\begin{array}{l}\text { Trabalham } \\
\text { com } \\
\text { Agricultura } \\
\text { Familiar } \\
\end{array}$} & Sim & 40 & 75,47 \\
\hline & Não & 13 & 24,53 \\
\hline
\end{tabular}

Fonte: Dados da pesquisa.

Também, foi verificado que suas respectivas esposas auxiliam, de alguma forma, nas atividades agrícolas exercidas nas propriedades. Predominantemente, o homem é o responsável pelos serviços braçais e as mulheres, além de geralmente cuidarem da casa os ajudam em algumas atividades no campo, contribuindo na renda por meio da confecção e venda de produtos caseiros, como: queijos, doces e frutos produzidos na propriedade.

A participação masculina é corroborada, conforme o trabalho de Araujo et al. (2007), no qual o percentual obtido foi de $74,5 \%$ para os homens e $25,5 \%$ para mulheres e pelo trabalho de Cinzenando (2012) em que 90,48\% eram homens.

A faixa etária dos proprietários foi variada, em que a maioria dos entrevistados tinha entre 46 a 60 anos $(43,40 \%$ dos entrevistados), seguido de $24,53 \%$, que representa a faixa entre 31 e 45 anos e 13,21\% entre 18 a 30 anos de idade. A faixa etária de proprietários rurais acima de 61 anos foi de $18,87 \%$. Notou-se que uma grande parte dos entrevistados era de aposentados, mas ainda exercem alguma função agrícola em suas propriedades.

Já no censo realizado pelo IBGE (2017), foi verificada que 
a faixa etária dos produtores até 25 anos representam 2,03\% do total, de 25 a menos de 35 anos 9,49\%, de 35 a menos de 45 anos $18,29 \%$, de 45 a menos de 55 anos $24,77 \%$, de 55 a menos de 65 anos $24,01 \%$ e de 65 ou mais $21,41 \%$.

A maioria dos entrevistados apresentou baixa escolaridade, com Ensino Fundamental incompleto, totalizando 25 dos 53 entrevistados. Além desses, 12 proprietários rurais cursaram o Ensino Médio completo e 3 deles incompletos, já com Ensino Fundamental completo tiveram apenas 2 representantes. Outros 11 entrevistados apresentaram Curso Superior completo, embora a maioria dos cursos de graduação não pertença a área agrícola, tais como: contadores, administradores, professores e advogado. A maioria desses relata "ter adquirido seu aprendizado de lidar com a terra de pai para filho". Muitos deles falaram "que a faculdade que cursaram era a faculdade da vida".

Baseado no Censo do SEBRAE (2012), os produtores rurais têm escolaridade concentrada em "Ensino Fundamental Incompleto" (81,4\%). Pouco mais de 10\% deles têm Ensino Médio completo ou mais, sendo um público menos escolarizado do que os empreendedores urbanos. Fato esse que pode influenciar diretamente na forma como a terra é administrada, pois pessoas com maior escolaridade tendem a participar mais de cursos de capacitação e de aperfeiçoamento. Outro ponto é que pessoas de baixa escolaridade tendem a permanecerem na agricultura, visto que teriam menos oportunidades nos centros urbanos.

Segundo a Pesquisa Hábitos do Produtor Rural (ABMRA, 2017), produzida pela empresa de consultoria Informa Economics, o produtor rural no Brasil tem em média 46,5 anos. Os dados também revelam que a mulher ganhou mais participação nesse cenário, representando $31 \%$ dos produtores - 21\% a mais em relação à pesquisa anterior. Assim, no geral, o produtor rural brasileiro é uma pessoa de meia idade, com filhos cursando a faculdade na área de agronegócio. Além da televisão e do rádio, esse empreendedor utiliza a internet, jornais e revistas para se manter atualizado com as novas práticas do setor.

\subsection{Percepção sobre o tamanho das propriedades}

A maioria $(75,47 \%)$ dos produtores rurais entrevistados trabalha com agricultura familiar, principalmente, os que apresentam áreas inferiores a 50 hectares e os conhecimentos de como manejar a terra são passados de geração a geração. O que corrobora com os dados obtidos por Gregolis et al. (2012), em que há um predomínio do trabalho rural do tipo familiar, com um total de $88 \%$ de trabalhadores rurais do município ocupados em atividades agropecuárias e com laços de parentesco com os proprietários da terra.

Na questão "como o proprietário se vê: grande, médio ou pequeno produtor", a maioria se considera como um pequeno produtor $(79,25 \%)$, independentemente do tamanho de suas propriedades que variou entre 1 e 500 hectares. Desses, $9(16 \%)$ entrevistados se consideram de médio porte, já os produtores de grande porte tiveram a menor representação com apenas 2 entrevistados.

A percepção de tamanho da propriedade pode ocorrer com base na utilização que os proprietários fazem dessa, tendo em vista que aqueles que têm produção em maior escala podem perceber suas propriedades como de médio a grande porte, os demais, por produzirem voltados para a sua subsistência, podem se considerar como produtores de pequeno porte. Isso decorre do processo de modernização agrícola, como cita Roesler (2009), alguns agricultores adotaram pacotes tecnológicos, contribuindo para mudança na sua base de produção e de capitalização, outros adaptaram as novas tecnologias e tiveram resultados diferentes, assim como houve agricultores, que ficaram excluídos tecnicamente, economicamente e socialmente desse processo.

As entrevistas foram conduzidas em propriedades que variavam de tamanho entre 1 a 1.200 hectares, sendo em sua maioria entre 11 a 50 hectares $(50,94 \%)$, propriedades com áreas de 1 a 10 hectares tiveram uma representação de 20,75\%, 51 a 500 hectares representaram 18,87\% e as propriedades, que tiveram o menor número de entrevistados, foi de 501 a 1.200 hectares pertencentes a somente 5 dos 53 entrevistados.

A classificação dos imóveis rurais está presente na Lei $\mathrm{n}^{\circ}$ 8.629/1993 (Art. 4, II e III), que define pequena propriedade como o imóvel de área compreendida entre 1 e 4 módulos fiscais e média propriedade como o imóvel rural de área superior a 4 e até 15 módulos fiscais, ficando entendido que o minifúndio é o imóvel rural com área inferior a 1 módulo fiscal, e a grande propriedade aquela de área superior a 15 módulos fiscais.

Por sua vez, a definição de agricultor familiar e empreendedor familiar rural dada pela Lei $n^{\circ} 11.326 / 2006$ também inclui o conceito de módulo fiscal, ao estabelecer que, entre outros requisitos, este não detenha, a qualquer título, área maior do que 4 módulos fiscais (EMBRAPA, 2012). Nesse sentido, considerando os dados acima, para o munícipio de Sinop, cada módulo fiscal abrange 90 hectares, caracterizando como agricultor familiar aquele que possui propriedade de até 360 hectares.

\subsection{Culturas produzidas na área}

As culturas que são produzidas nas propriedades variaram e apresentaram mais de 16 tipos de cultivos. Em geral, as pequenas propriedades possuíam predominância de cultivo de hortaliças, frutas e criação de frango e gado, já as propriedades maiores possuíam a sucessão de soja e milho.

Nas entrevistas realizadas, a soja e o milho foram as mais plantadas entre as culturas citadas. Quanto à criação de animais, gado foi a mais expressiva, seguida de frango e suíno. Para cultivos que requerem menor espaço, maior mão de obra e cuidados em sua produção como hortaliças que possuíam maior representação, seguido das frutas. Nas menores representações ficaram as culturas de milheto, feno, cana-deaçúcar, flores, árvores ornamentais e madeira (Quadro 3). 
Quadro 3 - Cultura agrícola ou criação realizadas pelos produtores rurais entrevistados que recebem ou não orientação técnica em suas propriedades no município de Sinop - MT, no período de julho e agosto de 2017

\begin{tabular}{|c|c|c|}
\hline Culturas / Criação & Entrevistados & \% \\
\hline Soja & 17 & 32,08 \\
\hline Milho & 18 & 33,96 \\
\hline Milheto & 2 & 5,66 \\
\hline Feno & 1 & 1,89 \\
\hline Hortaliças & 42 & 79,24 \\
\hline Fruta & 13 & 24,53 \\
\hline Cana-de-açúcar & 1 & 1,89 \\
\hline Arroz, Feijão & 2 & 3,77 \\
\hline Madeira & 1 & 1,89 \\
\hline $\begin{array}{c}\text { Flores e árvores } \\
\text { ornamentais }\end{array}$ & 1 & 1,89 \\
\hline Gado & 17 & 33,08 \\
\hline Frango & 5 & 9,43 \\
\hline Suíno & 2 & 3,77 \\
\hline
\end{tabular}

Fonte: Dados da pesquisa.

Importante destacar que cada cultura produzida pelas famílias, tendo em vista que muito do que se produz é para consumo próprio, alimentação dos animais e outras funções, contribuem para a renda familiar, seja na venda ou evitando que tal produto precise ser comprado, o qual é corroborado por Bezerra e Schlindwein (2017), que relataram a importância da diversificação na geração de renda e fixação do homem no meio rural - renda essa obtida pela venda e pela não aquisição de produtos em mercados (autoconsumo). Já Gomes et al. (2014) acrescentam que a diversificação da produção, além de uma estratégia de geração de renda pelos agricultores familiares ao longo do ano, é fundamental para o equilíbrio ecológico e para os sistemas agrícolas, considerando a sazonalidade de produção de cada espécie cultivada.

Conforme constatado, a cultura mais citada foi a de hortaliças $(79,24 \%)$, isso porque essas servem tanto para o consumo da família quanto para venda dos excedentes para auxílio na renda familiar. Consequentemente, tem papel fundamental para a atividade agrícola familiar, já que contribui para o seu fortalecimento e garante a sua sustentabilidade (FAULIN; AZEVEDO, 2003). Além disso, os produtores demonstraram enorme satisfação e orgulho de sua propriedade e de suas atividades, em especial, quando relatam da possibilidade de consumo de produtos naturais e saudáveis a família e aos consumidores/clientes, para manter uma condição de vida saudável e de bem-estar, pelo dinamismo da propriedade e estabilidade econômica, com um bom padrão de vida e a possibilidade de dar oportunidade aos filhos como uma alternativa de vida e ter sua própria atividade (BESEN et al., 2018).

A produção de frutas nas propriedades também é significativa $(24,53 \%)$, corroborando com o fato de que o Brasil é conhecido, em todo o mundo, por ser um dos maiores produtores do mundo. A fruticultura, através de uma grande variedade de culturas, conquista resultados expressivos e gera oportunidades para os pequenos produtores brasileiros (SABIO et al., 2015).

A agricultura de base ecológica tem a capacidade de, simultaneamente, cumprir com os preceitos da sustentabilidade econômica, ecológica, social e cultural, pois tem potencial de renda e trabalho, melhora a qualidade dos recursos naturais, prioriza a segurança alimentar e respeita e valoriza as culturas tradicionais (LOPES; LOPES, 2011).

\subsection{Uso de Equipamentos de Proteção Individual - EPIs}

Quanto ao uso de Equipamentos de Proteção Individual (EPIs), 31 entrevistados declararam usarem todos os equipamentos na hora de aplicação dos agrotóxicos, número que ainda é considerado baixo, pelo fato das substâncias serem nocivas à saúde e do risco do trabalhador rural com intoxicações graves.

Dos 53 entrevistados, três não usam qualquer tipo de proteção na aplicação dos agrotóxicos. Proprietários que usam apenas luva e máscara nas aplicações de agrotóxicos totalizaram 18,87\%; luva, máscara e óculos 15,09\% e luva, máscara e macacão $1,89 \%$. Muitos desses proprietários não usam os EPIs por completo, pois "utilizam pouco agrotóxico em sua propriedade, e que apenas pequenas proporções da substância não fazem mal[...]"

A proteção por meio do uso de equipamentos/vestimentas para a manipulação de agrotóxicos é outra questão que descortina o elevado grau de exposição de trabalhadores rurais. Souza et al. (2016) relataram que cerca de $80 \%$ dos produtores não usam adequadamente os equipamentos de proteção individual como botas e luvas de borracha, máscara com filtro, touca árabe, avental, calça, jaleco e viseira.

Embora nem todos os entrevistados usem todos os EPIs indicados pelos fabricantes de agrotóxicos, $90 \%$ deles reconheceram a importância de seu uso, sendo que todos os motivos alegados estão relacionados, exclusivamente, à questão de saúde. Nesse mesmo trabalho, alguns produtores rurais $(10 \%)$ declararam não usarem EPI algum e justificaram sua escolha por considerarem que esses "não oferecem proteção alguma" (25\%), ou "atrapalham o desempenho do serviço" (75\%). Recena e Caldas (2008) verificaram que 57\% dos entrevistados declararam usar todos os equipamentos de proteção recomendados pelos fabricantes de agrotóxicos utilizados nas lavouras, enquanto que 33\% declararam usar apenas alguns desses.

Em conformidade ao exposto, Lima et al. (2015) afirmaram que os agricultores reclamam do desconforto dos EPIs em função das elevadas temperaturas, o que torna os equipamentos de proteção inadequados ao trabalho, além de ser mais um custo para o produtor.

A baixa utilização do uso de EPI é um fator que preocupa, independentemente, da razão dessa não utilização, pois se observa que nem todos os produtores rurais possuem 
orientação técnica sobre o manejo de agrotóxico, fazendo com que o EPI seja uma das únicas possibilidades de proteção desses trabalhadores.

\subsection{Sobra de caldas no tanque/pulverizador/bomba e tríplice lavagem}

Do total de entrevistados, 39 afirmaram que não há sobra de calda no tanque, no pulverizador ou bomba de aplicação após a sua utilização. Entretanto, quando existe, a maioria aplica os defensivos mais de uma vez no mesmo talhão. Afirmaram ainda que calculam a quantidade de calda necessária para cada talhão, para que não haja desperdício do produto. Proprietários rurais que guardam a sobra da calda para uma próxima aplicação somam $22,64 \%$, e alegam que, normalmente, fazem desta maneira. Entrevistados que descartam as sobras de calda ou a utilizam para outros fins somam 3,78\% (Figura 1).

Figura 1 - Destino dado a sobra da calda pelos produtores rurais entrevistados que recebem ou não orientação técnica em suas propriedades no município de Sinop - MT, no período de julho e agosto de 2017

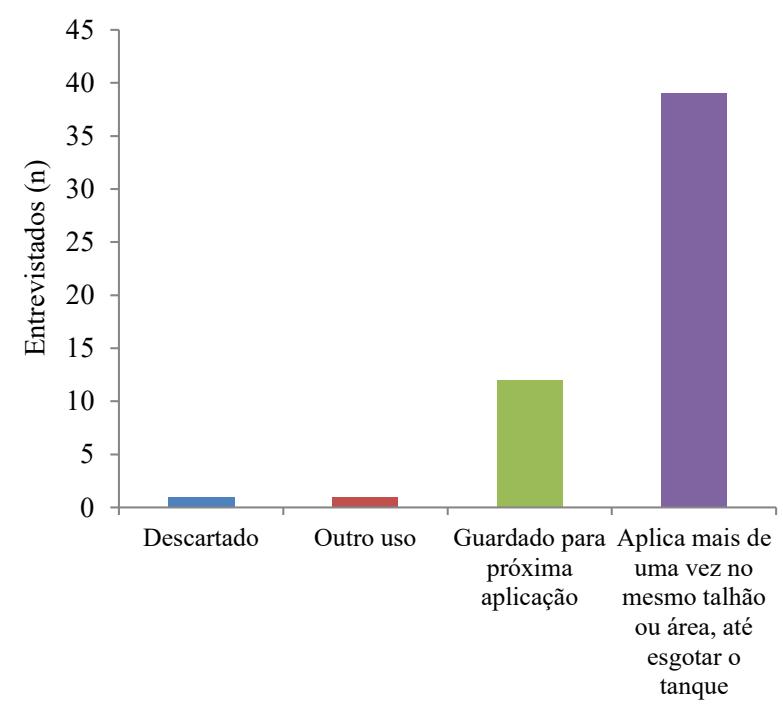

Fonte: Dados da pesquisa

A grande maioria dos proprietários rurais entrevistados tem ciência da importância da tríplice lavagem dos recipientes de agrotóxicos e sempre fazem o uso dessa prática (94,34\%); dois dos entrevistados relataram que às vezes é feito esse método de lavagem e um deles nunca fez o uso da tríplice lavagem, alegou que "nunca ouviu falar desse método, que apenas lava uma vez e separa o recipiente vazio para entregar na coletora perto de sua propriedade" (Quadro 4).

Quadro 4 - Respostas obtidas quanto à realização da tríplice lavagem, local de armazenamento e devolução das embalagens pelos produtores entrevistados

\begin{tabular}{|l|c|c|}
\hline É realizada a tríplice lavagem? & Entrevistados & \% \\
\hline Nunca & 1 & 1,89 \\
\hline Às vezes & 2 & 3,77 \\
\hline Sempre & 50 & 94,34 \\
\hline
\end{tabular}

\begin{tabular}{|l|c|r|}
\hline $\begin{array}{l}\text { Onde são armazenadas as } \\
\text { embalagens vazias? }\end{array}$ & & \\
\hline $\begin{array}{l}\text { Galpão fechado, de alvenaria, com } \\
\text { boa ventilação e iluminação natural }\end{array}$ & 13 & 24,53 \\
\hline Galpão de madeira & 37 & 69,81 \\
\hline Outro & 3 & 5,66 \\
\hline Devolve as embalagens vazias? & & \\
\hline Nunca & 5 & 9,43 \\
\hline Às vezes & 7 & 13,21 \\
\hline Sempre & 41 & 77,36 \\
\hline
\end{tabular}

Fonte: Dados da pesquisa.

Souza et al. (2016) constataram que apenas 40\% dos produtores costumam fazer a tríplice lavagem, 47\% nunca fizeram e 13\% fazem raramente o seu uso. Segundo Gonçalves et al. (2012) esse percentual é ainda menor na tribo indígena da Etnia Xukuru do Ororubá, pois apenas 5,4\% dos produtores realizam a tríplice lavagem em 24 aldeias entrevistadas.

Com relação à devolução de embalagens vazias, a maioria dos proprietários rurais $(77,36 \%)$ devolve nas unidades coletoras; $9,43 \%$ nunca devolvem e $13,21 \%$ às vezes devolvem (Quadro 4). Sete dos entrevistados alegaram que fazem outros usos para essas embalagens, como balde de peças, armazenamento de óleos, etc., e "que uma ou outra embalagem não faria falta a unidade coletora".

Marques et al. (2010), em seu trabalho sobre uso de agrotóxicos, relataram que $90 \%$ realizam o descarte das embalagens de agrotóxicos, conforme a legislação e 3,3\% queimam as embalagens após o uso. $\mathrm{O}$ armazenamento na propriedade e descarte em lixo comum foram citados por $6,7 \%$ dos entrevistados.

Quanto ao local de armazenamento de embalagens vazias, apenas $24,53 \%$ das propriedades rurais apresentaram estrutura adequada de armazenamento (Quadro 4), que é o galpão fechado, construído em alvenaria, com boa ventilação e iluminação natural exigida por lei (Lei $n^{\circ} 7.802$, de 11 de julho de 1989). Notou-se que as propriedades com esse tipo de adequação eram maiores, melhor estruturadas e com maior grau de tecnificação.

Propriedades que apresentavam galpão de madeira para armazenagem de embalagens vazias tiveram uma representação de $69,81 \%$, a maioria dessas propriedades era menor. Um dos produtores armazenava as embalagens vazias de defensivos agrícolas a céu aberto, por faltar estrutura adequada em sua propriedade, ele relata que "não deixa dentro do seu barracão para evitar intoxicações". Com outros locais de armazenagem, como fundo do barracão, teve uma representação de $3,77 \%$. Um dos entrevistados relatou que "queima as embalagens por falta de local de armazenagem mesmo sabendo que é ilegal e sujeito a multa".

\subsection{Presença de assistência técnica na propriedade}

Referente à assistência técnica recebida nas propriedades rurais se verificou que $37,74 \%$ dos produtores rurais não recebem nenhum tipo de assistência técnica ou orientação 
e a condução das atividades agrícolas era adquirida de seus conhecimentos e experiências no campo. Dos proprietários que recebem assistência técnica, 33,94\% recebem de engenheiro agrônomo, 22,64\% de técnico agrícola e 5,66\% recebem de ambos (Figura 2). Possível observar que essas propriedades, que receberam assistência técnica, eram propriedades mais estruturadas, e em termos de produtividade ficava aparente a diferença entre ter tido ou não orientação técnica.

Figura 2 - Número de produtores rurais entrevistados que recebem ou não orientação técnica em suas propriedades no município de Sinop - MT, no período de julho e agosto de 2017

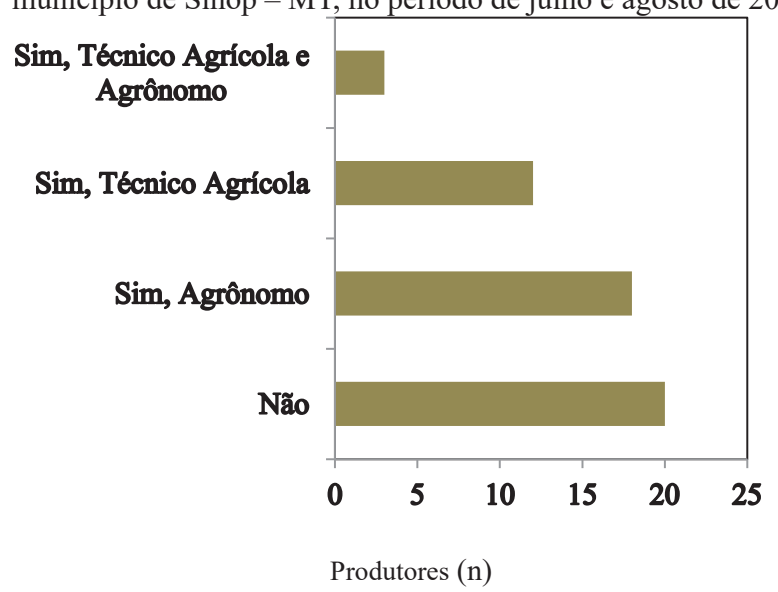

Fonte: Dados da pesquisa

Para os proprietários rurais que recebem assistência técnica $(\mathrm{n}=33), 60,60 \%$ vem de revendas de produtos agrícolas, $12,12 \%$ de cooperativas, $9,00 \%$ da EMPAER, 3,03\% do SENAR e $11,32 \%$ recebem orientação de outras fontes, além das citadas (Figura 3).

Figura 3 - Instituições que fornecem assistência técnica nas propriedades rurais entrevistadas no município de Sinop - MT no período de julho e agosto de 2017 . $\mathrm{N}=33$, em função de 20 deles informarem que não recebem assistência técnica

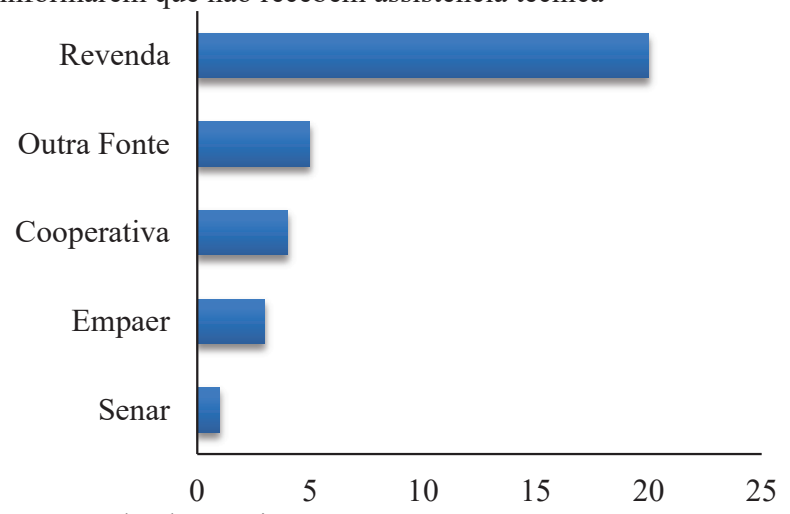

Fonte: Dados da pesquisa

A assistência técnica, geralmente, ocorre por parte de empresas de revenda de insumos agrícolas, que buscam esse contato para manter seu mercado. Nesse sentido, Duarte e Castro (2004) relataram que, em muitos casos, o contato que diversos agricultores têm com algum profissional das ciências agrárias ocorre unicamente com os agrônomos, veterinários, zootecnistas e técnicos agrícolas dessas revendas.
Castro (2015) afirma que no Sul do país existe a maior participação de agricultores membros de cooperativas e, como consequência, essa região tem um papel mais relevante em oferecer assistência técnica para seus associados. Bedor et al. (2009) destacaram que em função da quase ausência do acompanhamento técnico e no controle de agrotóxicos, o agricultor faz a tomada de decisão baseada quase que exclusivamente na produtividade, sem observar fatores relativos à saúde e ao meio ambiente. Besen et al. (2018) apresentaram a importância da assistência técnica, por meio da redução do uso de agrotóxico, de 70 a $80 \%$, em todos os 26 relatos dos produtores ( $100 \%$ dos entrevistados), mediante novas práticas de cultivo e condição das atividades agrícolas.

Quando questionado se o proprietário rural respeita o registro e o tempo de carência dos agrotóxicos para o consumidor final, 52 dos entrevistados responderam que sim, e apenas um entrevistado que não respeita.

Cizenando (2012) apresenta que a maioria dos entrevistados não respeita o período de carência dos defensivos agrícolas $(71,43 \%)$, embora recebam orientação de uso, e nem respeitam o período de reentrada na área. Dados esses corroborados por Araújo et al. (2000), em que afirmaram que $45,8 \%$ não respeitaram o tempo de carência necessário. Nesse sentido, mostra que é uma prática de difícil de controle e monitoramento do uso de agrotóxicos no campo, no qual pode acontecer o uso inadequado de ingredientes ativos ou na colheita antecipada do produto antes do término do período de carência do agrotóxico aplicado (GODOY; OLIVEIRA, 2004).

Referente aos possíveis casos de intoxicações nas propriedades, a maioria dos produtores rurais (94,34\%) nunca presenciou nenhum caso de intoxicação em suas propriedades. Em apenas 3 das propriedades visitadas já ocorreram casos de intoxicação, os sintomas relatados foram: vômitos, mal-estar e dor de cabeça. Os produtores alegaram tomar as devidas precauções na hora de manusear os defensivos agrícolas para evitar a intoxicação. Castro e Confalonieri (2005) relataram um índice de $22,5 \%$ de intoxicação por agrotóxicos e os sintomas mais comuns, mencionados pelos agricultores, foram: tonteira, dor de cabeça, dor no corpo e visão turva.

\subsection{Rotação de cultura}

Proprietários rurais, que não utilizam a rotação de cultura nas propriedades visitadas, são a maioria, 31 dos entrevistados e se verificou que boa porcentagem desses proprietários era os que tinham as maiores extensões de terra. Muitos sabem da importância da rotação de cultura para controle de doenças e pragas na lavoura, porém alegam que é difícil a implantação de outras culturas, pois o mercado é restrito para outros produtos agrícolas.

Produtores que sempre utilizam a rotação de cultura e aqueles que utilizam o sistema às vezes tiveram igual representação de 20,75\% cada. Diferentemente das propriedades maiores, nas quais predominava o sistema 
de sucessão de cultura, as menores apresentam maior representação de rotação, principalmente, nas áreas que cultivam hortaliças. Carvalho et al. (2007) citam que a prática da sucessão de culturas protege o solo contra a erosão e proporciona melhor aproveitamento no uso de adubos e eleva a atividade biológica do solo e controle das plantas daninhas.

\subsection{Controle biológico de pragas}

A maioria dos produtores rurais (37 entrevistados) já ouviu falar do controle biológico de pragas, seja pela televisão, internet, revistas, agrônomos, técnicos ou até mesmo por outros produtores, mas apenas 15 desses produtores usam ou usaram algum tipo de controle biológico de pragas em suas propriedades. Seus conhecimentos sobre o tema são restritos a apenas 3 dos 15 proprietários, que sabiam responder qual o tipo de controle foi utilizado em suas lavouras: $3,77 \%$ usaram baculovírus e 1,89\% Dipel ${ }^{\circledR}$. Os demais produtores nunca ouviram falar sobre o assunto e nunca utilizaram essa técnica de controle em suas propriedades (Figura 3).

Quando questionados sobre ter vontade de utilizar o controle biológico de pragas em suas propriedades, 19 responderam que sim, 9 responderam não e 25 responderam que talvez. Alguns apresentaram interesse em saber mais sobre o assunto, principalmente, os pequenos produtores, pois alegaram querer diminuir o uso de agrotóxicos, buscando alternativas de controle de pragas e de doenças menos danosas a saúde (Figura 4).

Figura 4 - Produtores rurais entrevistados (\%) no município de Sinop - MT que ouviram falar sobre o controle biológico (CB) de pragas, se já utilizaram o método e se gostariam de usar em suas propriedades

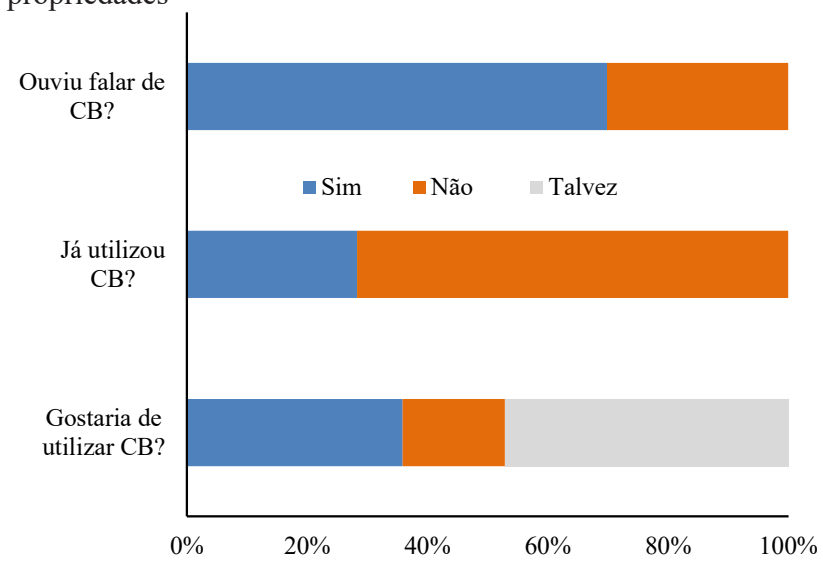

Fonte: Dados da pesquisa

Entrevistados

O controle biológico pode ser definido, simplificadamente, como um fenômeno natural ou introduzido que consiste na regulação do número de plantas e insetos por inimigos naturais, os quais se constituem nos agentes de mortalidade biótica (BERTI FILHO; MACEDO, 2010).

Berti Filho e Macedo (2010) descreveram que o uso de controle biológico, em larga escala, era um desafio para os produtores e entre as causas da baixa utilização citava a indisponibilidade de inimigos naturais e o custo da aplicação do controle biológico, que às vezes não era competitivo, quando comparado ao uso de agrotóxicos. Entretanto, segundo a Associação Brasileira das Empresas de Controle Biológico (ABCBio), a produção Brasileira de produtos biológicos para controle de pragas e doenças agrícolas cresceu mais de 70\% no ano de 2018, movimentando R\$ 464,5 milhões ante R\$ 262,4 milhões em 2017. Ainda, segundo a ABCBio, quase metade dos produtores brasileiros ainda desconhecem os produtos biológicos para controle de pragas e doenças nas lavouras e $39 \%$ já utilizam este tipo de manejo. Entre os agricultores que já adotam biodefensivos, 76\% apontam que consideram o controle biológico eficiente e $60 \%$ destacam a segurança da aplicação dos produtos biológicos.

Portanto, a agricultura familiar, que foi predominante neste estudo (mais de 70\%) é, além de um objeto político, uma forma social de produção, que se afirma para que a família detenha o controle da produção e realize as atividades produtivas. Mantendo as relações baseadas em laços de parentesco e/ ou laços afetivos de vizinhança, formando um arranjo social particular, enquanto forma de produção. A agricultura familiar, de pequena escala, exige presença contínua, proximidade com as culturas e detém uma matriz produtiva baseada em um “saber-fazer" (MARSCHNER, 2012).

Segundo Besen et al. (2018), o próprio saber tradicional é constantemente modificado por meio de novas experiências, informações, técnicas, e isso, além de promover a heterogeneidade na agricultura, permite que se estabeleça uma interface mais dinâmica, uma relação entre as demandas culturais e econômicas dos agricultores e os recursos disponíveis no meio ambiente.

A organização da produção em torno de um arranjo social próprio e que permeia a vida social dos produtores marca a noção de propriedade e pertencimento ao território. A propriedade rural passa a ser o local de intermediação dos seus costumes, valores, saberes e crenças. Desta forma, a produção agrícola, em pequena escala, consiste em um movimento de territorialização da produção e distribuição de alimentos, reforçando significados estabilizados, mas distintos daqueles reproduzidos pela produção em larga escala e reproduzidos pelos fluxos culturais de modernidade global (THOMPSON; COSKUNER-BALLI, 2007).

Contudo, apesar da relevância destes produtores, ao focar nas condições da agricultura familiar, entende-se que o universo no qual estes agricultores estão inseridos se encontra em uma posição díspar em relação ao agronegócio. Significados relacionados à família e à subsistência sobressaem nestas pequenas propriedades, e são distantes daqueles significados associados à lógica produtivista do agronegócio. Como, por exemplo, o que foi percebido que, grande parte dos produtores rurais não recebe algum tipo de assistência técnica, e aqueles que recebem são oriundas das revendas de produtos necessários à produção.

Políticas públicas voltadas para a estimulação da produção 
de alimentos saudáveis sem uso de agrotóxicos podem até mesmo favorecer a inclusão de agricultores marginalizados no atual modelo produtivo (PORTO; SOARES, 2012). Entretanto, recai sobre os pequenos agricultores a responsabilidade de conversão para sistemas de produção agrícola, baseados em princípios agroecológicos, tal como era feito antes do amplo uso de agrotóxicos, pois estes produtores estão mais aptos que produtores agrícolas convencionais.

Assim, o conhecimento tradicional sob formas de produção poderá ser resguardado e repassado, mantendo viva a cultura de produzir sem o uso intensivo de agrotóxicos. Em uma perspectiva mais ampla, a agroecologia reconhece a importância do conhecimento e da cultura das populações locais, bem como a importância de integrar a sustentabilidade ambiental com a justiça social, incorporando as dimensões sociais e culturais (CAPORAL, 2008; GLIESSMAN, 2001).

\section{Conclusão}

A maioria das propriedades entrevistadas é composta por homens de idade entre 46 a 60 anos, com Ensino Fundamental incompleto, que se consideram produtores de pequeno porte, trabalham com agricultura familiar e com culturas variadas e criação de gado.

Quase todos usam os equipamentos de proteção individual (EPIs), mesmo que parcialmente, costumam fazer uso da tríplice lavagem, respeitar o registro e o período de carência dos produtos utilizados e o principal local de armazenagem das embalagens vazias é o galpão de madeira, até a sua devolução.

Dos entrevistados, 33 recebem assistência técnica e essas orientações são fornecidas, principalmente, por meio de revendas de produtos agrícolas.

Muitos deles ouviram falar sobre controle biológico de pragas, mas somente uma pequena parte dos produtores já utilizou em suas propriedades e 83,20\% apresentaram algum interesse em utilizar o controle biológico.

Embora sejam agricultores familiares $(<70 \%)$, a lógica produtiva segue o mesmo padrão de grandes proprietários de terra, pois replicam as práticas usadas pela agricultura convencional em busca de maior produtividade, fazendo, assim, uso intensivo de agrotóxicos. Dessa maneira, os conhecimentos que possuem sobre as formas de produção sem a utilização de defensivos agrícolas vão sendo esquecidas e não repassadas para as gerações seguintes.

Enfim, o saber tradicional evolui continuamente e favorece a heterogeneidade na agricultura, ou seja, é um novo estilo de agricultura - um novo saber - que se agregam para a melhoria da produção agrícola.

\section{Referências}

ABCBio - Associação Brasileira das Empresas de Controle Biológico. O crescimento do biocontrole na agricultura. https:// www.abcbio.org.br/blog/biocontrole/. 2019. Acesso em: 23 set. 2019

ABMRA - Associação Brasileira de Marketing Rural e
Agronegócio. Pesquisa Hábitos do Produtor Rural. 2017. Disponível em: $<\mathrm{http}: / /$ informaecon-fnp.com/noticia/13269> Acesso em: 12 ago. 2019.

ALENCAR, G. et al. Percepção Ambiental e Uso do Solo por Agricultores de Sistemas Orgânicos e Convencionais na Chapada da Ibiapaba, Ceará. Rev. Econ. Soc. Rur., v.51, n.2. p.217-236, 2013. doi: 10.1590/S0103-20032013000200001

ARAÚJO, A.C.P.; NOGUEIRA, D.P.; AUGUSTO, L.G.S. Impacto dos praguicidas na saúde: estudo da cultura de tomate. Rev. Saú. Púb., v.34, n.3, p.309-313, 2000 doi: 10.1590/S003489102000000300016

ARAUJO, J.Á. et al. Exposição múltipla a agrotóxicos e efeitos à saúde: estudo transversal em amostra de 102 trabalhadores rurais, Nova Friburgo, RJ. Ciênc. Saú. Col., v.12, n.1, p.115-130, 2007. doi: 10.1590/S1413-81232007000100015

BEDOR, C.N.G. et al. Vulnerabilidades e situações de riscos relacionados ao uso de agrotóxicos na fruticultura irrigada. Rev. Bras. Epid., v.12, n.1, p.39-49, 2009. doi: 10.1590/S1415790X2009000100005.

BERTI FILHO, E.; MACEDO, L.P.M. Fundamentos de controle biológico de insetos-praga. Natal: IFRN Editora, 108 p. 2010.

BESEN, F.G. et al. Políticas públicas para a agricultura familiar no município de Entre Rios do Oeste: uma análise a partir da teoria ator orientado. Nativa, v.6, n.5, p.466-479, 2018. doi: 10.31413/nativa.v6i5.6775

BEZERRA, G.J.; SCHLINDWEIN, M.M. Agricultura familiar como geração de renda e desenvolvimento local: uma análise para Dourados, MS, Brasil. Interações, v.18, n.1, p.3-15, 2017. doi: 10.20435/1984-042X-2016-v.18-n.1(01)

CAPORAL, F. Em defesa de um Plano Nacional de Transição Agroecológica: compromisso com as atuais e nosso legado para as futuras gerações. Brasília: Embrapa. 2008. Disponível em: http://www.cpatsa.embrapa.br:8080/public_eletronica/ downloads/OPB2449.pdf

CARVALHO, M.A.C. et al. Plantas de cobertura, sucessão de culturas e manejo do solo em feijoeiro. Bragantia, v.4, n.66, p.659-668, 2007. doi: 10.1590/S0006-87052007000400016.

CASTRO, C.N. Desafios da agricultura familiar: O caso da assistência técnica e extensão rural. Boletim Regional, Urbano e Ambiental. Ipea, v.12, p.49-59, 2015.

CASTRO, J.S.M.; CONFALONIERI, U. Uso de agrotóxicos no Município de Cachoeiras de Macacu (RJ). Ciên. Saú. Col., v.10, n.2, p.473-482, 2005.

CIZENANDO, T.A.L. Uso de agrotóxicos nas pequenas propriedades produtoras de banana no municipio de Ipanguacu/ $R N$. Angico: UFERSA, 2012.

DELGADO, G.C.; BERGAMASCO, S.M.P.P. Agricultura familiar brasileira: desafios e perspectivas de futuro. Brasília: Ministério do Desenvolvimento Agrário, 2017.

DUARTE, J. E CASTRO, A.M.G. Comunicação e tecnologia na cadeia produtiva da soja em Mato Grosso. Brasília: Embrapa Informação Tecnológica, 2004.

EMBRAPA, Empresa Brasileira de Pesquisa Agropecuária. Variação geográfica do tamanho dos módulos fiscais no Brasil. Sete Lagoas: Embrapa Milho e Sorgo, 199p. 2012. Disponível em: <http://aiba.org.br/wp-content/uploads/2013/11/variacaoGeografica-do-Tamanho-dos-Modulos-Fiscais-no-BrasilEmbrapa.pdf> Acesso em: 19 out. 2019.

FARIAS, A.B. Contexto sócio histórico e econômico no Norte de Mato Grosso - caso de Sinop: a expansão da fronteira agrícola. Em Tempo de Histórias, v.31, p.84-100, 2017. 
FAULIN, E.J.; AZEVEDO, P.F. Distribuição de hortaliças na agricultura familiar: uma análise das transações. Infor. Econ., v.33, n.11, p.24-37, 2003.

GLIESSMAN, S. Agroecologia: processos ecológicos em agricultura sustentável. Porto Alegre: UFRGS, 637p. 2001.

GODOY, R.C.B.; OLIVEIRA, M.I. Agrotóxicos no Brasil: processo de registro, riscos à saúde e programas de monitoramento. Cruz das Almas: Embrapa Mandioca e Fruticultura Tropical, 2004.

GOMES, J.B.P. et al.Produção orgânica no Assentamento Itamarati, em Ponta Porã, estado de Mato Grosso do Sul, Brasil. Cad. Agroec., v.9, n.4, p.1-12, 2014.

GONÇALVES, G.M.S. et al. Uso de agrotóxicos e a relação com a saúde na etnia Xukuru do Ororubá, Pernambuco, Brasil. Saú. Soc. v.21, n.4, p.1001-1012, 2012.

GREGOLIS, T.B.L.; PINTO, W.J.; PERES, F. Percepção de riscos do uso de agrotóxicos por trabalhadores da agricultura familiar do município de Rio Branco, AC. Rev. Bras. Saú. Ocup., v.37, n.125, p.99-113, 2012. doi: 10.1590/S0303-76572012000100013

IBGE, Instituto Brasileiro de Geografia e Estatística. Censo Agro 2017: resultados preliminares mostram queda de $2,0 \%$ no número de estabelecimentos e alta de $5 \%$ na área total. Disponível em: $\quad<$ https://agenciadenoticias.ibge.gov.br/agencia-sala-deimprensa/2013-agencia-de-noticias/releases/21905-censoagro-2017-resultados-preliminares-mostram-queda-de-2-0-nonumero-de-estabelecimentos-e-alta-de-5-na-area-total. > Acesso em: 4 nov. 2019.

LIMA, L.B.et al. Uso de agroquímicos na produção de hortaliças em Farias Brito - CE. Braz. Jou. Appl. Tech. Agric. Scie., v.8, n.3, p.87-92, 2015. doi: 10.5935/PAeT.V8.N3.10

LOPES, P.R.; LOPES, K.C.S.A. Sistemas de produção de base ecológica - a busca por um desenvolvimento rural sustentável. REDD - Rev. Esp. Diál. Desc., v.4, n.1, p.1-32, 2011. doi: 10.32760/1984-1736/REDD/2011.v4i1.5047

MARQUES, C.R.G.; NEVES, P.M.O.J.; VENTURA, M.U. Diagnóstico do conhecimento de informações básicas para o uso de agrotóxicos por produtores de hortaliças da Região de Londrina, Semina: Ciên. Agrá., v.31, n.3, p.547-556, 2010.

MARSCHNER, W. Sobre saberes e sabores. In: PINHEIRO, A.S,; TEDESCHI, L.A.; MARSCHNER, W. Saberes da terra: teoria e vivências. Dourados: Ed. UFGD, 2012.

MENDES, E. do N. et al. O uso de agrotóxicos por agricultores no município de Tianguá-Ce. Agrop. Cien. Semiá., v.10, n.1, p.713, 2014. doi: 10.30969/acsa.v10i1.368
MENEZES, E.L.A. Controle biológico: na busca pela sustentabilidade da agricultura brasileira. Camp. Negó., v.3, p.6667, 2006.

NETTO, J.C.; DEGRANDE, P.E.; MELO, E.P. Seletividade de inseticidas e acaricidas aos inimigos naturais na cultura do algodão. Circular Técnica 14. 2014. Disponível em: <http:// www.imamt.com.br/system/anexos/arquivos/269/original/ circular_tecnica_edicao14_bx.pdf?1422971836> Acesso em: 12 nov. $20 \overline{19}$.

PORTO, M.F.; SOARES, W.L. Modelo de desenvolvimento, agrotóxicos e saúde: um panorama da realidade agrícola brasileira e propostas para uma agenda de pesquisa inovadora. Rev. Bras. Saú. Ocup., v.37, n.125, p.17-50, 2012.

RECENA, M.C.P.; CALDAS, E.D. Percepção de risco, atitudes e práticas no uso de agrotóxicos entre agricultores de Culturama, MS. Rev. Saú. Púb., v.42, n.2, p.294-301, 2008. doi: 10.1590/ S0034-89102008000200015

ROESLER, D.A. Racionalidades e práticas administrativas do agricultor familiar no contexto ambiental: um estudo em três comunidades rurais do sul da região metropolitana de Curitiba Paraná. Curitiba: UFPR, 2009.

SABIO, R.P. et al. Anuário Hortifruti Brasil - Retrospectiva 2015 \& Perspectiva 2016.

SALAMONI, G. Produção familiar camponesa: a agroecologia como estratégia frente à integração aos complexos agroindustriais. In: WIZNIEWSKY, C.R.F.; DAVID, C. Agricultura e transformações socioespaciais: olhares geográficos e a pesquisa de campo. Porto Alegre: Evangraf/Jadeditora, 2015.

SEBRAE Serviço Brasileiro de Apoio às Micro e Pequenas Empresas. Perfil do produtor rural. 2012. Disponível em: $<$ http:// www.sebrae.com.br/Sebrae/Portal\%20Sebrae/Anexos/perfil_do_ produtor_rural_-2012_.pdf> Acesso em: 24 out. 2019.

SOUZA, J.A. et al. Percepção dos produtores rurais quanto ao uso de agrotóxicos. Rev. Bra.Agric. Irrig., v.10, n.5, p.976-989. 2016. doi: 10.7127/RBAI.V10N500484

THOMPSON, C.J.; COSKUNER-BALLI, G. Countervailing market responses to corporate co-optation and the ideological recruitment of consumption communities. J. Cons. Res., v.34, n.2, p.135-152, 2007. doi: 10.1086/519143

VEIGA, M.M. Agrotóxicos: eficiência econômica e injustiça socioambiental. Ciên. Saú. Col., v.12, n.1, p.145-152, 2007. doi: 10.1590/S1413-81232007000100017

VINUTO, J.A. Amostragem em bola de neve na pesquisa qualitativa: um debate em aberto. Temáticas, v.22, n.44, p.203$220,2014$. 